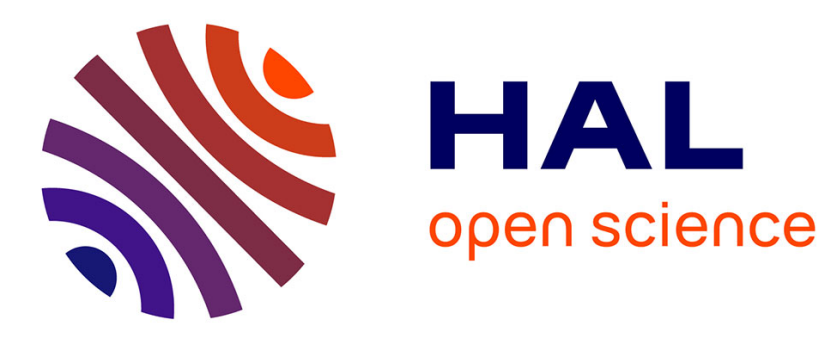

\title{
Evidence of Mixed-Valence Hydrated Europium-Chloride Phase in Vacuum by Means of Optical and Electronic Spectroscopies
}

Mathieu G Silly, Stephanie Blanchandin, Fausto Sirotti, François Lux, Sylviane Chevreux, Gilles Lemercier, Fabrice Charra

\section{To cite this version:}

Mathieu G Silly, Stephanie Blanchandin, Fausto Sirotti, François Lux, Sylviane Chevreux, et al.. Evidence of Mixed-Valence Hydrated Europium-Chloride Phase in Vacuum by Means of Optical and Electronic Spectroscopies. Journal of Physical Chemistry C, 2013, 117, pp.9766 - 9771. $10.1021 /$ jp312500f . cea-01478836

\section{HAL Id: cea-01478836 https://hal-cea.archives-ouvertes.fr/cea-01478836}

Submitted on 28 Feb 2017

HAL is a multi-disciplinary open access archive for the deposit and dissemination of scientific research documents, whether they are published or not. The documents may come from teaching and research institutions in France or abroad, or from public or private research centers.
L'archive ouverte pluridisciplinaire HAL, est destinée au dépôt et à la diffusion de documents scientifiques de niveau recherche, publiés ou non, émanant des établissements d'enseignement et de recherche français ou étrangers, des laboratoires publics ou privés. 


\title{
Evidence of Mixed-Valence Hydrated Europium-Chloride Phase in Vacuum by Means of Optical and Electronic Spectroscopies
}

\author{
Mathieu G. Silly, ${ }^{* \dagger}{ }^{\dagger}$ Stéphanie Blanchandin,$^{\dagger}$ Fausto Sirotti, ${ }^{\dagger}$ François Lux, ${ }^{\ddagger}$ Sylviane Chevreux, ${ }^{\S}$ \\ Gilles Lemercier, ${ }^{\S}$ and Fabrice Charra" \\ ${ }^{\dagger}$ Synchrotron SOLEIL, St Aubin, BP 48, 91192 Gif-sur-Yvette Cedex, France \\ ${ }^{\ddagger}$ Laboratoire de Physico-Chimie des Matériaux Luminescents (LPCML), bât. J. Raulin, 22 avenue Gaston Berger, Domaine de la \\ Doua, 69622 Villeurbanne Cedex, France \\ ${ }^{\S}$ Université Reims Champagne-Ardenne, ICMR UMR CNRS n ${ }^{\circ} 7312$; Coordination Chemistry Group, C ${ }^{2}$ POM Team, BP 1039 , \\ 51687 Reims Cedex 2, France \\ "Laboratoire de Nanophotonique, Service de Physique et Chimie des Surfaces et Interfaces (SPCSI), Institut Rayonnement Matière \\ de Saclay (IRAMIS), CEA, F-91191 Gif-sur-Yvette Cedex, France
}

ABSTRACT: Studying the optical and electronic properties of commercial hydrated $\mathrm{EuCl}_{3}$ salts, we took advantage of the manifestation of the unfilled $4 \mathrm{f}$ valence shell in photoluminescence and core-level photoemission spectroscopies to unambiguously identify contributions from both $\mathrm{Eu}^{3+}$ and $\mathrm{Eu}^{2+}$ configurations. Lanthanide ion salt exhibits sharp spectral lines in good agreement with $\mathrm{Eu}^{3+}$ oxidized state. Surprisingly, the photoemission spectrum of europium $4 \mathrm{~d}$ core level presents a singular asymmetric shape component attributed to $\mathrm{Eu}^{2+}$ species, thus revealing a significant amount of divalent europium. X-ray absorption spectroscopy confirmed the presence of $\mathrm{Eu}^{2+}$ species in proportions that depend on the origin of the salt and on the applied material processing.

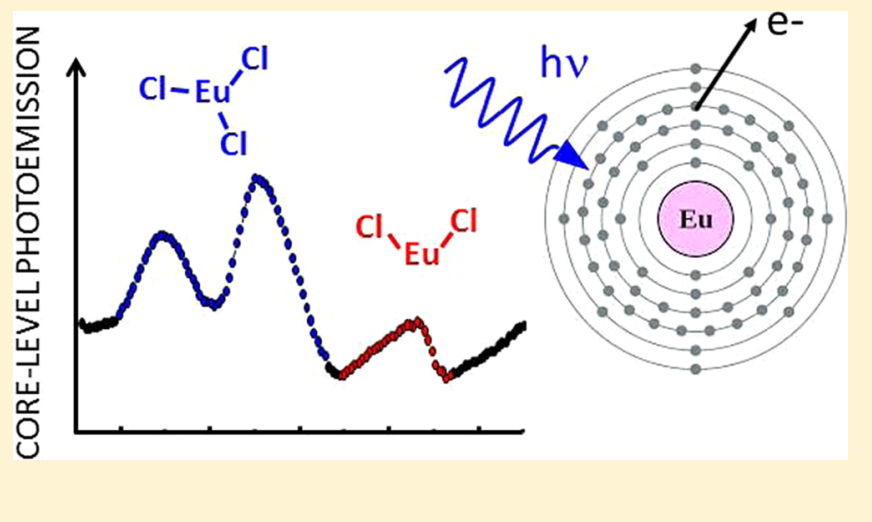

radiatively in the visible spectral range. Ligands such as water molecules and hydroxyle ions behave as nonradiative quenchers of ${ }^{5} \mathrm{D}_{4}$ and ${ }^{5} \mathrm{D}_{0}$ excited states. ${ }^{17}$ More generally, in contrast with other lanthanide ions, $\mathrm{Eu}^{3+}$ luminescence presents high sensitivity to environment. In particular, the ${ }^{5} \mathrm{D}_{0} \rightarrow{ }^{7} \mathrm{~F}_{2}$ socalled hypersensitive transition exhibits variations in terms of key characteristics such as intensity, quantum conversion efficiency, or luminescence decay depending on the chemical environment. Actually, although the partially filled $4 \mathrm{f}$ core shell responsible for the luminescence is expected to be weakly environment sensitive because of the shielding by the surrounding filled $5 \mathrm{~s}$ and $5 \mathrm{p}$ shells, luminescent characteristics of $\mathrm{Eu}^{3+}$ based complexes are known to depend significantly on the ligand-field symmetry and the nature of the ligands such as water or other solvents. ${ }^{18}$ Recent experiments have shown the direct implication of $\mathrm{O}, \mathrm{Cl}$, and $\mathrm{H}$ interaction with the europium ion in luminescence properties of $\mathrm{EuCl}_{3} \cdot 6 \mathrm{H}_{2} \mathrm{O} .{ }^{19}$

Europium possesses another substable oxidation state $\mathrm{Eu}^{2+}$, the electronic configuration of which, for the lowest excited state, is changed to $4 \mathrm{f}^{6} 5 \mathrm{~d}^{1}$ rather than $4 \mathrm{f}^{6}$ for $\mathrm{Eu}^{3+}$. This outer $5 \mathrm{~d}$ subshell is much more sensitive to the surrounding

Received: December 19, 2012

Revised: April 19, 2013

Published: April 21, 2013 
environment, such as anions or ligands, than the deep-lying $4 \mathrm{f}$ electrons, and always split to several sublevels according to its crystal or ligand field symmetry. Therefore, $\mathrm{Eu}^{2+}$ exhibits a broad emission band corresponding to $4 \mathrm{f}^{6} 5 \mathrm{~d}^{1} \rightarrow 4 \mathrm{f}^{7}$ in the UV, with often poor quantum efficiencies. ${ }^{20}$ Yet, partial reduction of $\mathrm{Eu}^{3+}$ to $\mathrm{Eu}^{2+}$ or the reverse oxidation is very likely to occur during material processing. ${ }^{21,22}$ Since this may be detrimental to material performance, an accurate monitoring of the divalent to trivalent composition ratio is necessary. Because those compounds most often include both crystallization water and hydroxide ions, charge neutrality can hardly be exploited from chemical or elemental analysis. Moreover, because of poor absorption cross-section and strong quantum-yield dependence on environment, optical measurements yield large uncertainties. $\mathrm{X}$-ray photoemission from $\mathrm{Eu}$ ions, which is mainly sensitive to the inner shells, ${ }^{23}$ can thus be anticipated to offer an alternative technique to monitor the oxidation-state composition of europium compounds in vacuum, during various material processing operations.

In this article, we report a combined photoluminescence and $\mathrm{X}$-ray photoemission study of the chemical oxidation states of commercial hydrated $\mathrm{EuCl}_{3}$ salts. Photoemission and X-ray absorption spectroscopies reveal the presence of trivalent but also divalent europium species in vacuum. The comparison of ratios between europium $2+$ and $3+$ species in salts of different origins by means of core level photoemission and X-ray absorption matches the differences observed in their chemical analysis of $\mathrm{Eu}$ and $\mathrm{Cl}$ species ratio.

\section{EXPERIMENTAL METHODS}

Experiments were performed using two commercial $\mathrm{EuCl}_{3} \cdot 6 \mathrm{H}_{2} \mathrm{O}$ salts (Acros and Sigma Aldrich, 99.9\% purity). $\mathrm{Eu}$ content measurements in each sample were carried out using ICP-AES technique on a Liberty Series II (Varian); three replicates for each analysis run, and $443.556 \mathrm{~nm}$ detection wavelength. Calibration was performed using a Eu standard solution for ICP-AES and-MS (SCP Science). Eu samples were prepared by solubilization of $\mathrm{EuCl}_{x}$ in water, and each sample was measured in duplicate. Chloride analyses were performed using ionic chromatography (Dionex). Sample preparation for spectroscopic analyses consisted in salt solubilization in dry ethanol, drop casting on gold substrate, and crystallization by evaporation of the solvent at $50{ }^{\circ} \mathrm{C}$ under $\mathrm{N}_{2}$ gas flux. The substrates were $100 \mathrm{~nm}$ thick layers of gold epitaxially grown on mica. The $22 \times \sqrt{3}$ reconstructed surface of gold(111) is obtained by $\mathrm{H}_{2}$ flame annealing at atmospheric pressure at a temperature around $450{ }^{\circ} \mathrm{C}$. The substrates were prepared immediately before drop casting. Photoluminescence was measured using an Ocean Optics HR2000+ spectrometer. The sample was excited by a continuous-wave laser (Coherent, Cube 405). This compact semiconductor laser system emits up to $100 \mathrm{~mW}$ at $405 \mathrm{~nm}$ in a TEM00 mode. Photoemission spectroscopy experiments were performed at the French Synchrotron Soleil at the soft X-ray TEMPO beamline. ${ }^{24}$ The spectral resolution of the beamline $\Delta E / E$ is better than 10000 over the whole photon energy range $40-1500 \mathrm{eV}$. A hemispherical electron analyzer Scienta 2002 equipped with a fast delay line detector is used to measure photoelectron spectroscopy spectra. Photoabsorption spectra were determined from sample current measured with picoamperemeters and normalized to gold mesh signal (60\% transmission). Measurements were performed at a pressure lower than $3 \times$ $10^{-10}$ mbars.

\section{RESULTS AND DISCUSSION}

A chemical dosing of proportion of chlorine and europium ions for $99.9 \%$ ultrahigh purity $\mathrm{EuCl}_{3} \cdot 6 \mathrm{H}_{2} \mathrm{O}$ salt has been performed. Surprisingly, as Sigma Aldrich europium salt was presenting an expected proportion of three chlorines for one europium and six surrounding $\mathrm{H}_{2} \mathrm{O}$ molecules, the dosing of the $\mathrm{Eu}$ and $\mathrm{Cl}$ species in Acros salt has shown a proportion of $2.85 \pm 0.05$ chlorines for one europium ion. This composition could be interpreted either in terms of a mixture of $85 \%$ of $\mathrm{Eu}^{3+}$ species and $15 \%$ of $\mathrm{Eu}^{2+}$ species or in terms of the presence of alternative negative counterions, such as oxide $\mathrm{O}^{2-}$ or hydroxides $\mathrm{OH}^{-}$. The latter seems more probable since, exposed to air, the less stable $\mathrm{Eu}^{2+}$ species is known to react with $\mathrm{O}_{2}$ and $\mathrm{H}_{2} \mathrm{O}$ to be oxidized as $\mathrm{Eu}^{3+25}$ forming possible hydroxychlorides and oxychlorides. Spectroscopic investigation of the lanthanide salt may give insights in the interpretation of this unexpected lack of chlorine species and determine the equilibrium composition. In addition, a number of ten to 11 $\mathrm{H}_{2} \mathrm{O}$ molecules surrounding the $\mathrm{EuCl}_{x}(2<x<3)$ salt has been found. Lanthanide compounds present highly hygroscopic properties. In the rest of the discussion, hydrated $\mathrm{EuCl}_{3}$ salt will refer to the Acros europium salt and Sigma Aldrich europium salt will be mentioned and used as $\mathrm{EuCl}_{3} \cdot 6 \mathrm{H}_{2} \mathrm{O}$ reference.

In air, the hydrated $\mathrm{EuCl}_{3}$ salt luminescence spectra obtained after excitation at $405 \mathrm{~nm}$ through the ${ }^{5} \mathrm{~L}_{6}$ level is shown in Figure 1 . The spectrum exhibits a relatively sharp line emission

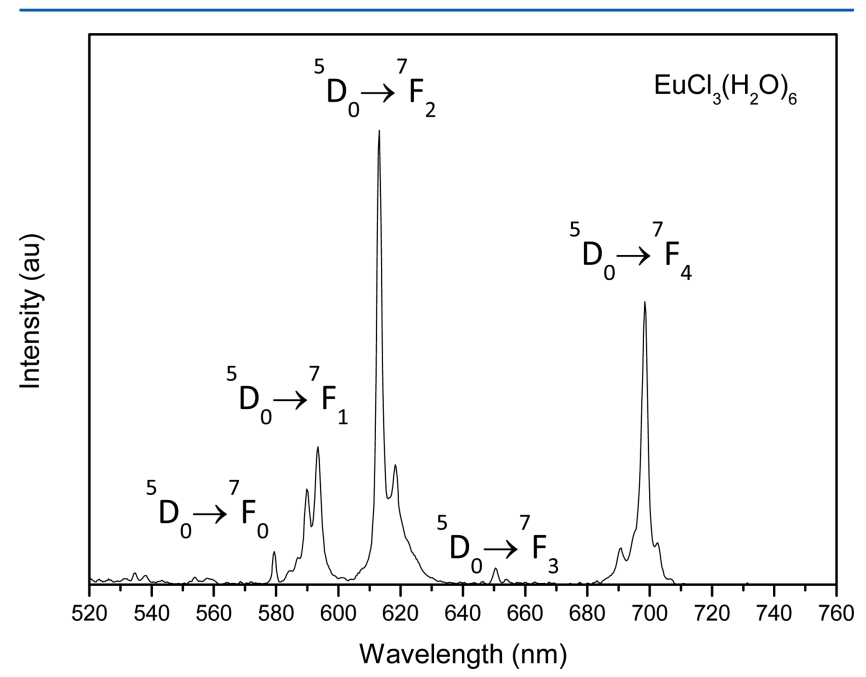

Figure 1. Room temperature photoluminescence spectrum of hydrated $\mathrm{EuCl}_{3}$ salt deposited on gold substrate under $405 \mathrm{~nm} \mathrm{CW}$ laser excitation.

structure. As for $\mathrm{Eu}(\mathrm{III})$ complexes in aqueous solution, major luminescence of hydrated $\mathrm{EuCl}_{3}$ salt originates from nondegenerate ${ }^{5} \mathrm{D}_{0}$ level.

The number of observed line splittings for the different ${ }^{5} \mathrm{D}_{0}$ $\rightarrow{ }^{7} \mathrm{~F}_{n}$ transitions complies with the allowed $2 J+1$ splitting peaks, i.e., at most $1,3,5$, and 9 peaks for ${ }^{5} \mathrm{D}_{0} \rightarrow{ }^{7} \mathrm{~F}_{n}$ transitions with $n=0,1,2$, and 4 , respectively. This result, associated with relatively sharp line splitting patterns and intense ${ }^{5} \mathrm{D}_{0} \rightarrow{ }^{7} \mathrm{~F}_{2}$ transitions, is in good agreement with a homogeneous single type of $\mathrm{Eu}^{3+}$ ion and surrounding noncentrosymmetric arrangement. ${ }^{26}$ Luminescent properties of europium depend on its detailed chemical environment and electronic configuration. Compared to the luminescence of europium trichloride hexahydrate and thermal decomposition products, ${ }^{27}$ the sharp 
asymmetric shape of the measured ${ }^{5} \mathrm{D}_{0} \rightarrow{ }^{7} \mathrm{~F}_{2}$ transitions well matches with the luminescence of a $\mathrm{EuCl}_{3} \cdot 6 \mathrm{H}_{2} \mathrm{O}$ salt, with neither evidence of $\mathrm{Eu}(\mathrm{OH}) \mathrm{Cl}_{2}$ signal nor of divalent $\mathrm{Eu}^{2+}$ ion. However, the weak expected contributions from both types of species does not permit to definitely exclude one or the other of the hypotheses evoqued to interpret the lack of chloride counterions in this salt.

In order to obtain further insights into electronic and chemical surroundings of europium ion in the salts, we have investigated the electronic properties of europium salt by means of core level photoemission. It is to be noticed that the necessary vacuum operation of this technique is very likely to influence the chemical composition, for instance, the hydration ratios, of the salts. Moreover, synchrotron radiation interaction with reactive materials is well-known to potentially reduce species under beam. Nevertheless, in our experiments, europium chloride appeared to be very stable under synchrotron radiation beam, and no modification of the core level spectra was observed during the acquisition. This does not preclude changes induced during application of vacuum, prior to photoemission measurements. However, the chemical sensitivity of the photoemission spectroscopy allows us to quantitatively establish the in-vacuum salt chemical composition. The Eu $4 \mathrm{~d}$ core level spectrum is shown in Figure 2: the

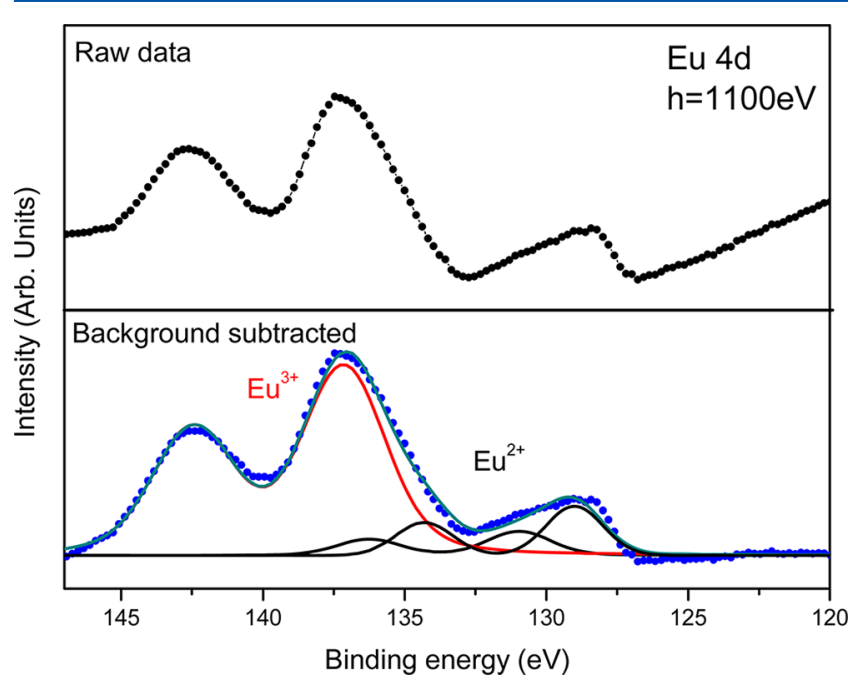

Figure 2. Hydrated $\mathrm{EuCl}_{3}$ salt deposited on gold substrate $\mathrm{Eu} 4 \mathrm{~d}$ core level photoemission spectrum measured at photonenergy $h \nu=1100$ $\mathrm{eV}$. Top, black dots and line represents $\mathrm{Eu} 4 \mathrm{~d}$ core level row data; bottom, in blue dots is shown Eu 4d raw data background removed spectrum. Red line corresponds to $\mathrm{Eu}^{3+}$ fitted component and black lines are related to $\mathrm{Eu}^{2+}$ species as first approximation. Dark cyan line is related to the sum of the different fitted components.

spectrum exhibits two main components located at higher binding energy attributed to trivalent europium and a second structure located at lower binding energy ascribed to $\mathrm{Eu}^{2+}{ }^{23}$ Whereas the first structure can be perfectly fitted with a Voigt function doublet with respect to europium $4 \mathrm{~d}$ spin orbit splitting and 2:3 ratio allocated, respectively, to $d_{3 / 2}$ and $d_{5 / 2}$ states and centered at $137.2 \mathrm{eV}$, the second structure about 129 $\mathrm{eV}$ assigned to $\mathrm{Eu}^{2+}$ states exhibits a more complicated asymmetric shape similar to Eu $4 \mathrm{~d}$ core level photoemission spectrum $^{28}$ incompatible with a single Voigt function doublet approximation. Such a structure has been previously measured for different divalent and trivalent rare earth metals. ${ }^{23,29,30}$
Although the origin of $\mathrm{Eu}^{3+}$ component is clearly determined, assignment of $\mathrm{Eu}^{2+}$ component is much more controversial.

Although for pure $\mathrm{EuCl}_{3}$ cleaved crystals, the appearance of $\mathrm{Eu}^{2+}$ signature may be ascribed to modified bonding configuration at the surfaces, ${ }^{23,29,30}$ hydrated $\mathrm{EuCl}_{3}$ ionic crystal deposited on gold surface is expected to preserve its local crystal configuration even at the surface. ${ }^{31}$ Actually, the system does not consist in a truncated crystal leading to lower oxidized states at the surface but is an assembly of isolated europium ions carrying their own surrounding counterions (see already published crystal structure of $\left.\left[\mathrm{EuCl}_{2}\left(\mathrm{H}_{2} \mathrm{O}\right)_{6}\right] \mathrm{Cl}^{32}\right)$. Moreover, we chose a large photoexcitation energy to measure the $4 \mathrm{~d}$ core level spectrum with a deeper penetration depth in order to minimize potential surface contribution. Additionally, $\mathrm{Eu}^{3+}$ is known to have the tendency to be reduced into $\mathrm{Eu}^{2+}$ species, which could explain the possible presence of divalent Eu after applying vacuum; ${ }^{33}$ in turn, this possible consequence of material processing procedures represents a well-known inconveniency in practical applications. In order to further settle the existence of a mixed $\mathrm{Eu}^{3+} / \mathrm{Eu}^{2+}$ oxidation states in the bulk, rather than a pure $\mathrm{Eu}^{3+}$ sample potentially exhibiting a $\mathrm{Eu}^{2+}$ contribution due to shake-off processes, a quantitative study of $\mathrm{Eu}^{3+}$ and $\mathrm{Eu}^{2+}$ species has been performed, beyond the lone $\mathrm{Eu} 4 \mathrm{~d}$ core level spectrum analysis.

To evaluate the amount of $\mathrm{Eu}^{2+}$ species compared to $\mathrm{Eu}^{3+}$ states, the $\mathrm{Eu}^{2+}$ asymmetric contribution has been fitted with two Voigt doublets. We have thus determined a $\mathrm{Eu}^{2+}$ concentration of $20.7 \%$. In order to clearly determine the location of the $\mathrm{Eu}^{2+}$ oxidation state species and discriminate between surface phenomenon and bulk $\mathrm{Eu}^{2+}$ and $\mathrm{Eu}^{3+}$ mixed ions, we have measured the Eu $3 \mathrm{~d}$ near edge X-ray absorption fine structure spectrum (NEXAFS). Compared to X-ray photoemission, XAS is much more bulk sensitive, and as other works shown, ${ }^{34,35}$ the amounts of each oxidation state can be determined from XAS spectra. Figure 3 represents the Eu $3 \mathrm{~d}-4 \mathrm{f}$ XAS experimental spectrum measured in total electron yield. The experimental XAS spectrum is analyzed and compared to calculated $3 \mathrm{~d}-4 \mathrm{f}$ absorption spectra for $\mathrm{Eu}^{2+}$ and $\mathrm{Eu}^{3+}$ states. The atomic multiplet calculations were performed using the CTM4XAS 5.23 program. $^{36}$ In the calculation, discrete energy states are broadened by a Lorentzian with a half width at half-maximum of $0.2 \mathrm{eV}$ to take into account core-hole lifetime and by a Gaussian with a half width at half-maximum of $0.6 \mathrm{eV}$ to account for instrumental resolution. A contribution of around 20\% of $\mathrm{Eu}^{2+}$ states gives a good matching between calculated and experimental spectra. This ratio of $\mathrm{Eu}^{2+}$ and $\mathrm{Eu}^{3+}$ oxidation states is consistent with the proportion determined with the Eu $4 \mathrm{~d}$ core level photoemission spectrum. This result shows that the balance of oxidation states is independent of probed sample depth and confirms a homogeneous repartition of the two oxidation states in the bulk of the sample. It is to be noticed that this ratio matches the results of the elemental analysis performed on the used europium salt sample, which gives a $\mathrm{Cl} /$ $\mathrm{Eu}$ ratio of $2.85 \pm 0.05$, which corresponds to about $15 \%$ $\mathrm{Eu}(\mathrm{II})$ and $85 \% \mathrm{Eu}(\mathrm{III})$ either as a composition of the pristine material or as a result of a partial $\mathrm{Eu}(\mathrm{III})$ reduction as $\mathrm{Eu}(\mathrm{II})$ following a vacuum elimination of the counterion other than chloride (e.g., following $4 \mathrm{OH}^{-} \rightarrow \mathrm{O}_{2}+2 \mathrm{H}_{2} \mathrm{O}+4 \mathrm{e}^{-}$, if hydroxide counterions are to be considered). As a reference, the absorption spectrum of Sigma Aldrich europium salt exhibiting a $\mathrm{EuCl}_{3} \cdot 6 \mathrm{H}_{2} \mathrm{O}$ chemical composition is presented in Figure $3 \mathrm{~b}$. The absorption spectrum presents a pure trivalent 


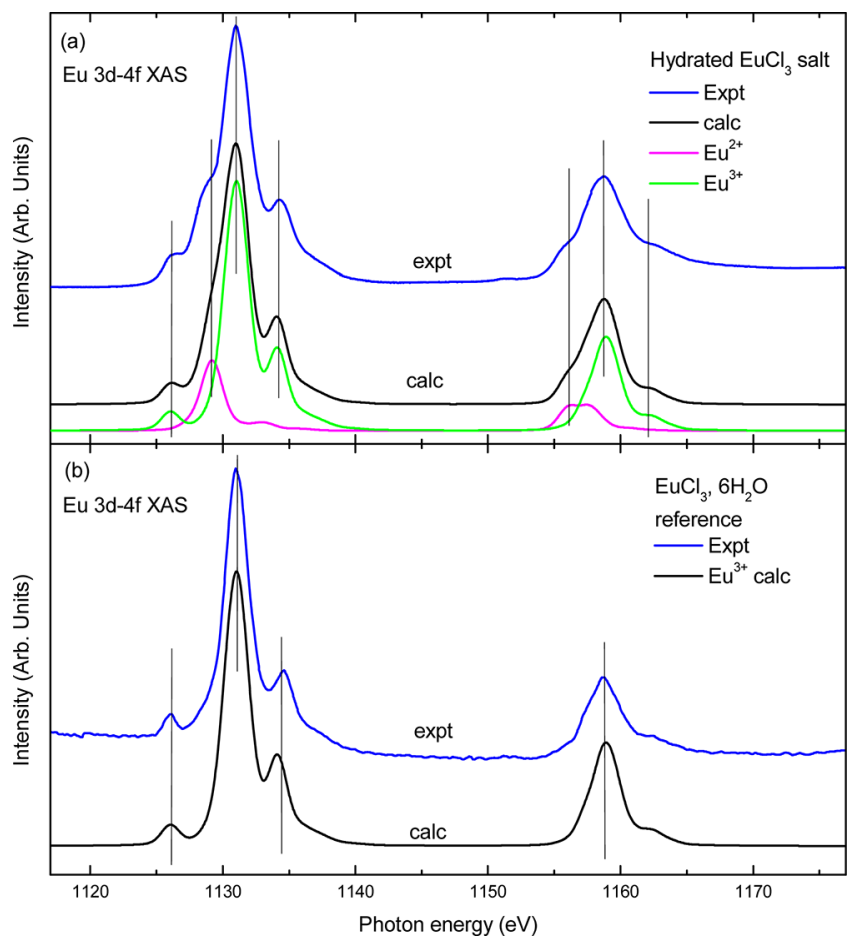

Figure 3. Comparison of the Eu 3d-4f XAS experimental spectrum and calculated spectra for (a) Acros hydrated $\mathrm{EuCl}_{3}$ salt and (b) Sigma Aldrich europium salts used as $\mathrm{EuCl}_{3} \cdot 6 \mathrm{H}_{2} \mathrm{O}$ reference. Calculated spectrum is a combination of atomic multiplet calculations of $\mathrm{Eu}^{2+}$ and $\mathrm{Eu}^{3+}$ ions using the CTM4XAS atomic multiplet program.

absorption spectrum and well matches with the $\mathrm{Eu}^{3+}$ atomic multiplet calculation. The comparison between the absorption spectra of the two different europium salts confirms the presence of divalent europium in Acros europium salt, after application of the vacuum.

$\mathrm{Cl} 2 \mathrm{p}$ core level has also been measured in order to ascribe the nature of the divalent and trivalent europium counterions. In lanthanide ion salt and, for instance, in the studied hydrated $\mathrm{EuCl}_{3}$ salt, the oxidation state is supposed to be directly related to $\mathrm{Cl}^{-}$ion interacting with $\mathrm{Eu}$ ion. On the basis of this hypothesis, the chlorine electronic structure should be affected by the two different $\mathrm{Eu}^{3+}$ or $\mathrm{Eu}^{2+}$ chemical environments. A study of the $\mathrm{Cl} 2 \mathrm{p}$ core level can definitely determine the origin of the $\mathrm{Eu}^{2+}$ contribution in $\mathrm{Eu} 4 \mathrm{~d}$ core level. The $\mathrm{Cl} 2 \mathrm{p}$ core level spectrum shown in Figure 4 presents a characteristic shape of $2 \mathrm{p}$ core level with conventional spin orbit splitting due to $2 \mathrm{p}_{1 / 2}$ and $2 \mathrm{p}_{3 / 2}$ degenerated components. The spectrum was fitted by means of Voigt doublet function with a spin orbit splitting of $1.7 \mathrm{eV}$ and an intensity ratio of the doublet peaks of $1: 2$ relevant for $\mathrm{p}_{1 / 2}$ and $\mathrm{p}_{3 / 2}$, respectively.

The $\mathrm{Cl} 2 \mathrm{p}$ spectrum is somewhat broadened compared to previous work on chlorine adsorption on molecular systems and $\mathrm{Cu}(100) \cdot{ }^{37}$ As on $\mathrm{Cu}(100), \mathrm{Cl} 2 \mathrm{p}$ core level presents a sharp and resolved 2-component structure consistent with a single chlorine species. $\mathrm{Cl} 2 \mathrm{p}$ spectrum presents a broadened 2component structure in the case of chlorine adsorption on molecular film deposited on $\mathrm{Cu}(100)$ surface showing more complicated interactions between $\mathrm{Cl}$ and molecules. To fit the $\mathrm{Cl} 2 \mathrm{p}$ core level, the use of two components is needed. This result is in clear contradiction with a pure $\mathrm{Eu}^{3+}$ composition of the salt.

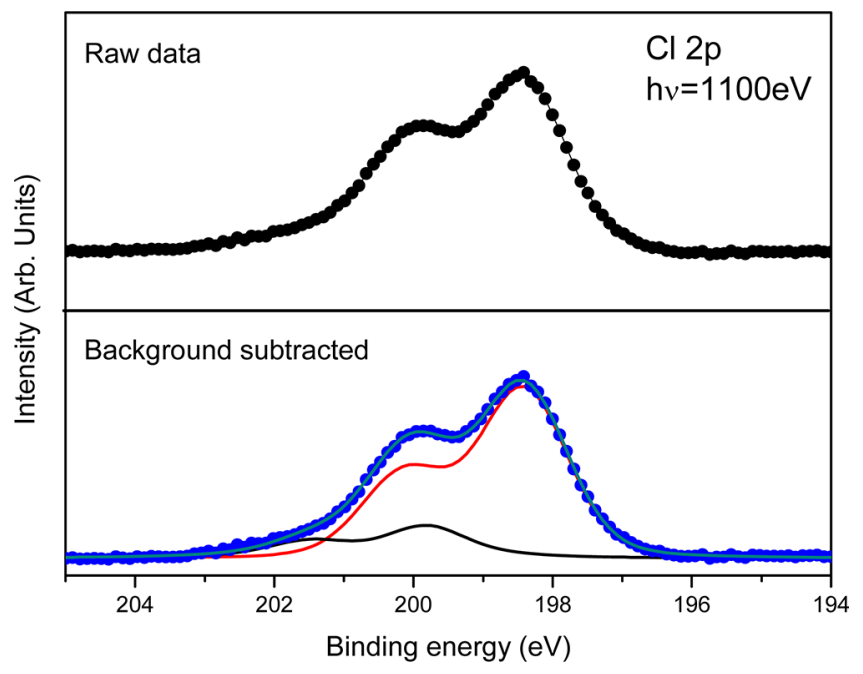

Figure 4. $\mathrm{Cl} 2 \mathrm{p}$ photoemission spectrum of hydrated $\mathrm{EuCl}_{3}$ salt deposited on gold substrate at photonenergy $h \nu=1100 \mathrm{eV}$. Top, black dots and line represents row data $\mathrm{Cl} 2 \mathrm{p}$ core level; bottom, in blue dots is shown $\mathrm{Cl} 2 \mathrm{p}$ raw data spectrum with subtracted background. Red and black lines correspond to two fitted components as described in the text. Dark cyan line tallies the sum of the two components.

The comparison between $\mathrm{Eu} 4 \mathrm{~d}$ and $\mathrm{Cl} 2 \mathrm{p}$ intensities can also give information concerning the amount of $\mathrm{Eu}^{3+}$ and $\mathrm{Eu}^{2+}$ species associated to two and three chlorine ions, respectively. $\mathrm{Cl} 2 \mathrm{p}$ core level spectra are fitted with two components: the first one, located at higher binding energy, presents its maximum at $198.44 \mathrm{eV}$ and represents in intensity area $82.3 \%$ of the total $\mathrm{Cl} 2 \mathrm{p}$ peak, whereas the second main component is centered at $199.83 \mathrm{eV}$, and its intensity area is equal to $17.7 \%$ of the total of the $\mathrm{Cl} 2 \mathrm{p}$ intensity. The component located at higher binding energy corresponds to chlorine linked to a more positively charged ion as a trivalent $\mathrm{Eu}$ species compared to chlorine situated at lower binding energy related to chlorine linked to a less charged $\mathrm{Eu}$ ion as a divalent species. The area intensity is in relatively good agreement, with respect to the uncertainty, with the intensity area ratio of $\mathrm{Eu}^{2+}(20.7 \%)$ and $\mathrm{Eu}^{3+}(79.3 \%)$ determined previously. A $\mathrm{Eu}^{2+} / \mathrm{Cl}^{-}$ratio of 1:2 leads to an expected percentage of $14.8 \%$ of chlorine linked to a divalent $\mathrm{Eu}$, while a $\mathrm{Eu}^{3+} / \mathrm{Cl}^{-}$ratio of $1: 3$ leads to an expected percentage of $85.2 \%$ of chlorine linked to a trivalent europium. Therefore, the different contributions in $\mathrm{Cl} 2 \mathrm{p}$ and $\mathrm{Eu} 4 \mathrm{~d}$ core level spectra further confirm a quantitative amount of divalent europium with a proportion close to the measured percentage of $20.7 \%$ of $\mathrm{Eu}^{2+}$ and $79.3 \%$ of $\mathrm{Eu}^{3+}$ species.

A presence of a non-negligible amount of oxygen species has been found by measuring $\mathrm{O}_{1 \mathrm{~s}}$ core level photoemission spectrum. Although consistent with the presence of the ten water molecules found with the elemental analysis (Figure 5), other ion interaction with europium such as $\mathrm{OH}^{-}$ion contributing to total europium charge cannot be excluded. The core level photoemission and X-ray absorption spectroscopies clearly show the spectroscopic signature of $\mathrm{Eu}^{2+}$ species indicating that after application of the vacuum on the deposited europium salt, the $\mathrm{Eu}^{2+}$ oxidation state in the adopted structural arrangement is extremely stable. Owing to the high sensitivity to oxygen species such as $\mathrm{H}_{2} \mathrm{O}$ and $\mathrm{O}_{2}$ of $\mathrm{Eu}^{2+}$ salts exposed to air, known to spontaneously react and oxidize as $\mathrm{Eu}^{3+}$, the $\mathrm{Eu}^{2+}$ divalent ions may appear during vacuum preparation of the 


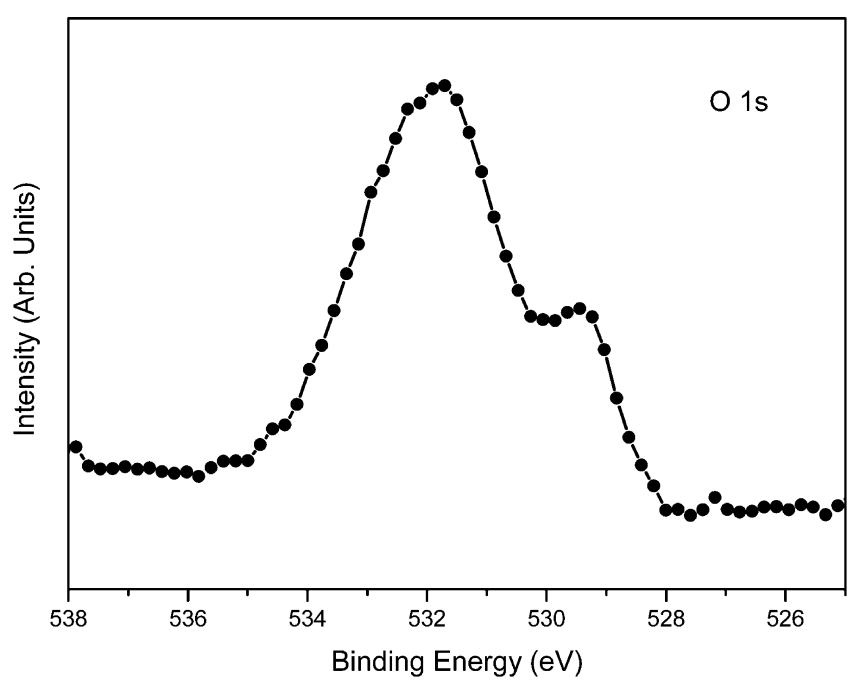

Figure 5. $\mathrm{O} 1 \mathrm{~s}$ photoemission spectrum of hydrated $\mathrm{EuCl}_{3}$ salt deposited on gold substrate $(h \nu=1100 \mathrm{eV})$.

sample, depending on the initial chemical composition of the pristine sample.

The matching between the $\mathrm{Eu} / \mathrm{Cl}$ elementary ratio determined by chemical dosing, core level photoemission and $\mathrm{X}$-ray absorption proves the correlation between initial chemical composition of the pristine salts and of the detected ratio of $\mathrm{Eu}^{2+}$ and $\mathrm{Eu}^{3+}$ species in the hydrated $\mathrm{EuCl}_{3}$ salt, after application of vacuum. Finally, let us mention that after annealing hydrated $\mathrm{EuCl}_{3}$ salt over $350{ }^{\circ} \mathrm{C}$ in UHV conditions, which permits to reduce the $\mathrm{Eu}^{3+}$ into $\mathrm{Eu}^{2+},{ }^{21}$ and subsequent exposed to air leading to hydration and reoxidation of the $\mathrm{Eu}^{2+}$ species into $\mathrm{Eu}^{3+}$. The measured $\mathrm{Eu} 4 \mathrm{~d}$ core level spectrum, Figure 6, presents the behavior of pure $\mathrm{Eu}^{3+}$ species without

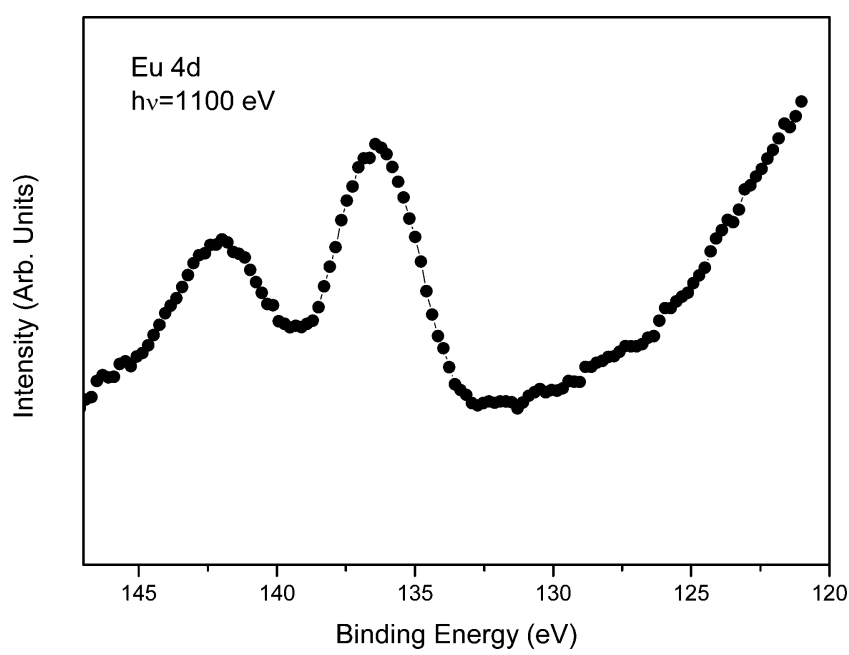

Figure 6. Eu $4 \mathrm{~d}$ photoemission spectrum of hydrated $\mathrm{EuCl}_{3}$ salt deposited on gold substrate $(h \nu=1100 \mathrm{eV})$ after UHV annealing over $350{ }^{\circ} \mathrm{C}$ followed by air exposure.

any noticeable $\mathrm{Eu}^{2+}$ contribution. Thus, the possible initial counterion previously lost under vacuum and responsible for the appearance of divalent $\mathrm{Eu}$, is not restored during exposition to air. The persistence of $\mathrm{Eu}^{3+}$ character after thermal treatment followed by hydration and oxidation in air may indicate an involved counterion in pristine hydrated $\mathrm{EuCl}_{3}$ salt other than hydroxide, in good agreement with measured photoluminescence (Figure 1).

In conclusion, we have shown that the photoluminescence spectrum of hydrated $\mathrm{EuCl}_{3}$ salt presents a sharp-line structure in good agreement with the ${ }^{5} \mathrm{D}_{0} \rightarrow{ }^{7} \mathrm{~F}_{n}(n=1$ to 4$)$ radiative transitions. The sharpness and the number of radiative lines fit with a homogeneous single type of $\mathrm{Eu}^{3+}$ ion and noncentrosymmetric surroundings. Under vacuum, core level photoemission spectroscopy revealed the presence of two types of europium ions. The asymmetric component of the spectrum is unambiguously attributed to $\mathrm{Eu}^{2+}$ ion. Divalent species represents around $15-20 \%$ of the total amount of europium ions. This proportion correlates with the elementary composition found by chemical dosing. We have hence undoubtedly identified mixed valence hydrated $\mathrm{EuCl}_{2.85}$ compounds, stable under vacuum.

\section{AUTHOR INFORMATION}

\section{Notes}

The authors declare no competing financial interest.

\section{REFERENCES}

(1) Bunzli, J. C. G.; Chauvin, A. S.; Kim, H. K.; Deiters, E.; Eliseeva, S. V. Lanthanide Luminescence Efficiency in Eight- and NineCoordinate Complexes: Role of the Radiative Lifetime. Coord. Chem. Rev. 2010, 254 (21-22), 2623-2633.

(2) Bunzli, J. C. G.; Comby, S.; Chauvin, A. S.; Vandevyver, C. D. B. New Opportunities for Lanthanide Luminescence. J. Rare Earth 2007, 25 (3), 257-274.

(3) Bunzli, J. C. G.; Piguet, C. Lanthanide-Containing Molecular and Supramolecular Polymetallic Functional Assemblies. Chem. Rev. 2002, 102 (6), 1897-1928

(4) Kido, J.; Okamoto, Y. Organo Lanthanide Metal Complexes for Electroluminescent Materials. Chem. Rev. 2002, 102 (6), 2357-2368.

(5) Bunzli, J. C. G. Lanthanide Luminescence for Biomedical Analyses and Imaging. Chem. Rev. 2010, 110 (5), 2729-2755.

(6) Parker, D.; Dickins, R. S.; Puschmann, H.; Crossland, C.; Howard, J. A. K. Being Excited by Lanthanide Coordination Complexes: Aqua Species, Chirality, Excited-State Chemistry, and Exchange Dynamics. Chem. Rev. 2002, 102 (6), 1977-2010.

(7) Cabello, G.; Lillo, L.; Caro, C. Europium: Compounds, Production and their Optical Applications. In Europium: Compounds, Production and Applications; Moreno, L. M., Ed.; Nova Science Publishers, Inc.: Hauppauge, NY, 2011, 103-142.

(8) Alpha, B.; Lehn, J. M.; Mathis, G. Energy-Transfer Luminescence of Europium(III) and Terbium(III) Cryptates of Macrobicyclic Polypyridine Ligands. Angew. Chem., Int. Ed. 1987, 26 (3), 266-267.

(9) Charbonniere, L.; Ziessel, R.; Guardigli, M.; Roda, A.; Sabbatini, N.; Cesario, M. Lanthanide Tags for Time-Resolved Luminescence Microscopy Displaying Improved Stability and Optical Properties. J. Am. Chem. Soc. 2001, 123 (10), 2436-2437.

(10) Comby, S.; Imbert, D.; Chauvin, A. S.; Bunzli, J. C. G.; Charbonniere, L. J.; Ziessel, R. F. Influence of Anionic Functions on the Coordination and Photophysical Properties of Lanthanide(III) Complexes with Tridentate Bipyridines. Inorg. Chem. 2004, 43 (23), 7369-7379.

(11) Chen, X. Y.; Bretonniere, Y.; Pecaut, J.; Imbert, D.; Bunzli, J. C.; Mazzanti, M. Selective Self-Assembly of Hexameric Homo- and Heteropolymetallic Lanthanide Wheels: Synthesis, Structure, and Photophysical Studies. Inorg. Chem. 2007, 46 (3), 625-637.

(12) Bottger, T.; Thiel, C. W.; Cone, R. L.; Sun, Y. Effects of Magnetic Field Orientation on Optical Decoherence in $\mathrm{Er}^{3+}: \mathrm{Y}_{2} \mathrm{SiO}_{5}$. Phys. Rev. B 2009, 79 (11), 115104.

(13) Alexander, A. L.; Longdell, J. J.; Sellars, M. J.; Manson, N. B. Photon Echoes Produced by Switching Electric Fields. Phys. Rev. Lett. 2006, 96 (4), 043602. 
(14) Longdell, J. J.; Fraval, E.; Sellars, M. J.; Manson, N. B. Stopped Light with Storage Times Greater than One Second Using Electromagnetically Induced Transparency in a Solid. Phys. Rev. Lett. 2005, 95 (6), 063601.

(15) de Riedmatten, H.; Afzelius, M.; Staudt, M. U.; Simon, C.; Gisin, N. A Solid-State Light-Matter Interface at the Single-Photon Level. Nature 2008, 456 (7223), 773-777.

(16) Dehorrocks, W.; Albin, M. Lanthanide Ion Luminescence in Coordination Chemistry and Biochemistry. Prog. Inorg. Chem. 1983, $31,1-104$.

(17) Binnemans, K. Lanthanide-Based Luminescent Hybrid Materials. Chem. Rev. 2009, 109 (9), 4283-4374.

(18) Bunzli, J. C. G.; Piguet, C. Taking Advantage of Luminescent Lanthanide Ions. Chem. Soc. Rev. 2005, 34 (12), 1048-1077.

(19) Ahlefeldt, R. L.; Smith, A.; Sellars, M. J. Ligand Isotope Structure of the Optical ${ }^{7} \mathrm{~F}_{0} \rightarrow{ }^{5} \mathrm{D}_{0}$ Transition in $\mathrm{EuCl}_{3} \cdot 6 \mathrm{H}_{2} \mathrm{O}$. Phys. Rev. B 2009, 80 (20), 205106.

(20) Kobayasi, T.; Mroczkowski, S.; Owen, J. F.; Brixner, L. H. Fluorescence Lifetime and Quantum Efficiency for 5D-4F Transitions in $\mathrm{Eu}^{2+}$ Doped Chloride and Fluoride-Crystals. J. Lumin. 1980, 21 (3), 247-257.

(21) Johnson, K. E.; Mackenzie., J. R. Anhydrous Chlorides of Some Rare Earths. J. Inorg. Nucl. Chem. 1970, 32 (1), 43-48.

(22) Zaitoun, M. A.; Goken, D. M.; Bailey, L. S.; Kim, T.; Lin, C. T. Thermoanalysis and Emission Properties of $\mathrm{Eu}^{3+} / \mathrm{Eu}^{2+}$ in $\mathrm{Eu}^{3+}$-Doped Xerogels. J. Phys. Chem. B 2000, 104 (2), 189-196.

(23) Schneider, W. D.; Laubschat, C.; Nowik, I.; Kaindl, G. Shake-up Excitations and Core-Hole Screening in Eu Systems. Phys. Rev. B 1981, 24 (9), 5422-5425.

(24) Polack, F.; Silly, M.; Chauvet, C.; Lagarde, B.; Bergeard, N.; Izquierdo, M.; Chubar, O.; Krizmancic, D.; Ribbens, M.; Duval, J. P.; Basset, C.; Kubsky, S.; Sirotti, F. TEMPO: a New Insertion Device Beamline at SOLEIL for Time Resolved Photoelectron Spectroscopy Experiments on Solids and Interfaces. AIP Conf. Proc. 2010, 1234, $185-188$.

(25) Friedrich, S.; Hertrich, T.; Drury, O. B.; Cherepy, N. J.; Hohne, J. A Superconducting Tunnel Junction X-ray Spectrometer Without Liquid Cryogens. IEEE Trans. Nucl. Sci. 2009, 56 (3), 1089-1096.

(26) Nassar, E. J.; Ciuffi, K. J.; Calefi, P. S.; Avila, L. R.; Bandeira, L. C.; Cestari, A.; de Faria, E. H. ; Marçal, A. L. ; Matos, M. G. Europium III: Different Emission Spectra in Different Matrices, the Same Element. In Europium: Compounds, Production and Applications; Moreno, L. M., Ed.; Nova Science Publishers, Inc.: Hauppauge, NY, 2011, 1-60.

(27) Stump, N. A.; Schweitzer, G. K.; Gibson, J. K.; Haire, R. G.; Peterson, J. R. Luminescence Study of the Thermal-Decomposition of Europium Trichloride Hexahydrate, $\mathrm{EuCl}_{3} \cdot 6 \mathrm{H}_{2} \mathrm{O}$. Appl. Spectrosc. 1994, 48 (8), 937-944.

(28) Gerth, C.; Godehusen, K.; Richter, M.; Zimmermann, P.; Schulz, J.; Wernet, P.; Sonntag, B.; Kochur, A. G.; Petrov, I. D. Multiplet and Lifetime Effects in the 4d Photoelectron Spectrum of Eu. Phys. Rev. A 2000, 61 (2), 022713.

(29) Laubschat, C.; Perscheid, B.; Schneider, W. D. Final-State Effects and Surface Valence in Eu-Transition-Metal Compounds. Phys. Rev. B 1983, 28 (8), 4342-4348.

(30) Cho, E. J.; Oh, S. J. Surface Valence Transition in Trivalent Eu Insulating Compounds Observed by Photoelectron Spectroscopy. Phys. Rev. B 1999, 59 (24), R15613-R15616.

(31) Wertheim, G. K.; Crecelius, G. Divalent Surface-State on Metallic Samarium. Phys. Rev. Lett. 1978, 40 (12), 813-816.

(32) Kepert, D. L.; Patrick, J. M.; White, A. H. Structure and Stereochemistry in F-Block Complexes of High Coordination-Number 0.7. the $\mathrm{M}$ (unidentate- $\mathrm{X}) 2$ (unidentate- $\mathrm{Y}$ )6 System Crystal-Structure of Hexaaquadichloroeuropium(III) Chloride (A Redetermination). Aust. J. Chem. 1983, 36 (3), 477-482.

(33) Binnemans, K. A Comparative Spectroscopic Study of $\mathrm{Eu}^{3+}$ in Crystalline Host Matrices. Bull. Soc. Chim. Belg. 1996, 105 (12), 793798.
(34) Yamamoto, K.; Horiba, K.; Taguchi, M.; Matsunami, M.; Kamakura, N.; Chainani, A.; Takata, Y.; Mimura, K.; Shiga, M.; Wada, H.; Senba, Y.; Ohashi, H.; Shin, S. Temperature-Dependent Eu 3d-4f $\mathrm{X}$-ray Absorption and Resonant Photoemission Study of the Valence Transition in $\mathrm{EuNi}_{2}\left(\mathrm{Si}_{0.2} \mathrm{Ge}_{0.8}\right)_{2}$. Phys. Rev. B 2005, 72 (16), 161101.

(35) Ruck, B. J.; Trodahl, H. J.; Richter, J. H.; Cezar, J. C.; Wilhelm, F.; Rogalev, A.; Antonov, V. N.; Do Le, B.; Meyer, C. Magnetic State of EuN: X-ray Magnetic Circular Dichroism at the Eu M-4,M-5 and L2,L-3 Absorption Edges. Phys. Rev. B 2011, 83 (17), 174404.

(36) Stavitski, E.; de Groot, F. M. F. The CTM4XAS Program for EELS and XAS Spectral Shape Analysis of Transition Metal L Edges. Micron 2010, 41 (7), 687-694.

(37) Breuer, S.; Pham, D. T.; Huemann, S.; Gentz, K.; Zoerlein, C.; Hunger, R.; Wandelt, K.; Broekmann, P. Organic Layers at Metal/ Electrolyte Interfaces: Molecular Structure and Reactivity of Viologen Monolayers. New J. Phys. 2008, 10, 125033. 